Jan Kanuch - Peter Girovsky*

\title{
ANALISIS OF THE PM MOTOR WITH EXTERNAL ROTOR FOR DIRECT DRIVE OF ELECTRIC WHEELCHAIR
}

The paper deals with analysis of properties of synchronous motor with external permanent magnets rotor. The mathematical analysis and equivalent circuit of permanent magnet synchronous motor (SMPM) is presented. In the parts of the paper the electromagnetic design, construction design and FEM Simulation of a SMPM is described and its properties are analysed. In the paper the results of simulation in Matlab/Simulink of torque, speed and current on the base mathematical model are shown.

Keywords: direct drive, electric vehicle, external rotor, permanent magnet machine, synchronous motor, wheelchair

\section{Introduction}

Due to some of its advantageous features, such as high efficiency, high torque-to-current ratio, low noise, and robustness has permanent magnets synchronous motor (PMSM) received widespread acceptance in industrial applications [1]. Electric machines present main parts of the electric vehicle power train, whilst demands for electric machines differ. In general, characteristics as large torque, high rotation speed, high power density, quick response and good reliability are in high demand. Synchronous machines supplied by electronic converter are first of all widely used as the permanent magnet synchronous machine in variable speed drives and applied to small electric vehicles [2].

The manufacturers produce small electric vehicles with various types of drives. Drives of small electric vehicles are nowadays the subject of research of many manufacturers and institutes [3]. Design solutions bring several alternatives that differ in technical parameters [4]. Most of the parameters of drive depend directly on design solutions of the electric motor, on its power, battery voltage, dimensions of frequency converter and others. The development of high-quality permanent magnet materials in commercial production has encouraged several manufacturers to introduce various PMSM to the market.

The most practical for the electric wheelchair is a direct drive that is a motor with an external rotor using permanent magnets in-wheel operation. The drive can be designed with an inverse DC motor with permanent magnets or an AC synchronous motor with permanent magnets an external rotor, respectively. Optimal design of synchronous motor parameters is influenced by utilization of inverters [5-6]. The study [7] examines the effects of motor parameters on the torque and speed capability.

The characteristics of a permanent magnet machine are highly dependent on the rotor structure. The rotor can be implemented in various ways. When employing modern permanent magnet materials, the rotor can be constructed even completely without iron.

Designed and produced for direct drive of the wheelchair has been the prototype of an inverse $\mathrm{AC}$ synchronous motor with permanent magnets [8] and this motor is assessed and simulated in the following parts of the paper.

\section{Mathematical analysis and equivalent circuit of permanent magnet synchronous motor}

As to the modelling, it is common practice to transform all variables from the three-phase system (abc) to an orthogonal (dq) reference frame with a direct (d) and quadrature (q) axis (see Figure 1), where $\mathrm{X}$ represents the voltage, current or magnetic flux and $\theta_{r}$ is the rotor angle.

Clarke Transformation $a b c \rightarrow \alpha \beta$, see Equation (1), and Park Transformation $\alpha \beta \rightarrow \mathrm{dq}$, see Equation (2), can be applied regarding reference frame theory.

$\left[\begin{array}{l}\alpha \\ \beta\end{array}\right]=\frac{2}{3} \cdot\left[\begin{array}{lll}1 & \cos (2 \pi / 3) & \cos (4 \pi / 3) \\ 0 & \sin (2 \pi / 3) & \sin (4 \pi / 3)\end{array}\right] \cdot\left[\begin{array}{l}a \\ b \\ c\end{array}\right]$,

$\left[\begin{array}{l}d \\ q\end{array}\right]=\left[\begin{array}{cc}\cos \left(\theta_{r}\right) & \sin \left(\theta_{r}\right) \\ -\sin \left(\theta_{r}\right) & \cos \left(\theta_{r}\right)\end{array}\right] \cdot\left[\begin{array}{l}\alpha \\ \beta\end{array}\right]$

The transformation of a three-phase quantity in abc-coordinate system to dq-system is called Clarke-Park's Transformation. Written in matrix form, see Equation (3), the Clarke-Park's Transformation is defined as

$$
\left[\begin{array}{l}
d \\
q
\end{array}\right]=\frac{2}{3} \cdot\left[\begin{array}{lll}
\cos \left(\theta_{r}\right) & \cos \left(\theta_{r}-2 \pi / 3\right) & \cos \left(\theta_{r}+2 \pi / 3\right) \\
\sin \left(\theta_{r}\right) & \sin \left(\theta_{r}-2 \pi / 3\right) & \sin \left(\theta_{r}+2 \pi / 3\right)
\end{array}\right] \cdot\left[\begin{array}{l}
a \\
b \\
c
\end{array}\right]
$$

Permanent magnet synchronous motors (PMSM) are usually modelled in the rotor reference frame, i.e. in the Clarke-Park's d-q model. In this synchronous reference frame, the PMSM with PM rotor is generally described by the following set of equations [8-9]:

$$
\begin{aligned}
& u_{d}=R \cdot i_{d}+L_{d} \cdot \frac{d i_{d}}{d t}-\omega L_{q} i_{q} \\
& u_{q}=R \cdot i_{q}+L_{q} \cdot \frac{d i_{q}}{d t}-\omega L_{d} i_{d}+\omega \psi_{M d} .
\end{aligned}
$$

\footnotetext{
* Jan Kanuch, Peter Girovsky

Department of Electrical Engineering and Mechatronics, Faculty of Electrical Engineering and Informatics, Technical University in Kosice, Slovakia E-mail: jan.kanuch@tuke.sk
} 


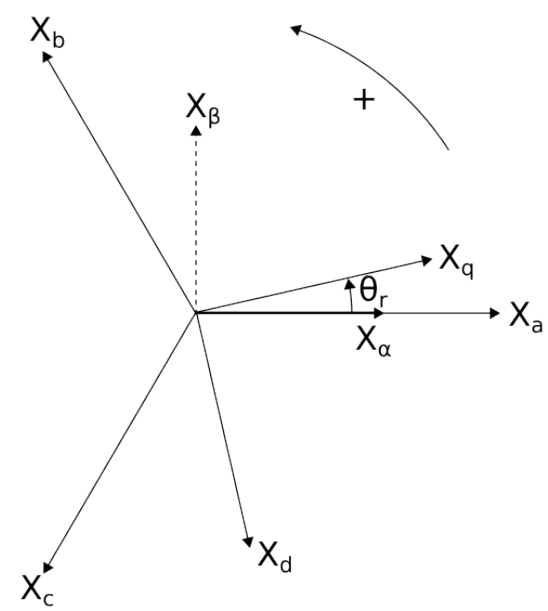

Figure 1 Rotating reference frames

where: $\quad u_{d}$ and $u_{q}$ are the $\mathrm{d}$ and $\mathrm{q}$ axes voltages, $i_{d}$ and $i_{q}$ are the $\mathrm{d}$ and $\mathrm{q}$ axes currents, $R$ is the stator resistance,

$\omega$ is the electrical angular speed,

$\Psi_{M d}$ is the permanent magnet flux,

$L_{d}$ and $L_{q}$ are inductances of the stator $\mathrm{d}$ and $\mathrm{q}$ axes.

The PMSM can be described in Equation (4) and (5) with the

following assumptions:

- saturation is negligible,

- the induced back EMF is sinusoidal,

- eddy currents and hysteresis losses are negligible,

- no field current dynamics,

- no cage on the rotor.

The electromagnetic torque can be expressed as follows:

$T_{e m}=\frac{3}{2} \cdot \frac{P}{2} \cdot\left[\psi_{M d} \cdot i_{d}-\left(L_{q}-L_{d}\right) \cdot i_{d} \cdot i_{q}\right]$.

where $P$ is the number of poles, $i_{d}$ and $i_{q}$ are the d-axis and q-axis components of the stator current vector. Thus, the magnitude of $I_{S}$ is given by equation:

$I_{S}=\sqrt{i_{d}^{2}+i_{q}^{2}}$.

The equivalent circuit of the PM machine shown in Figure 2 is similar to the one for the synchronous machine.

The permanent magnet is modelled by a current source $i_{m}$ parallel to the resistance $R_{M}$. In the magnetizing inductance, this current source produces the permanent magnet's share of the air gap flux linkage:

$\psi_{M d}=i_{m} \cdot L_{m d}$.

However, due to the saturation the magnetizing inductance $L_{m d}$ and $i_{m}$ are not constant. The flux linkage components in Figure 2 are determined by the equations:

$\psi_{d}=i_{d} \cdot L_{d}+\psi_{M d}=i_{d} \cdot\left(L_{1 d}+L_{m d}\right)+\psi_{M d}$,

$\psi_{q}=i_{q} \cdot L_{q}=i_{q} \cdot\left(L_{1 q}+L_{m q}\right)$
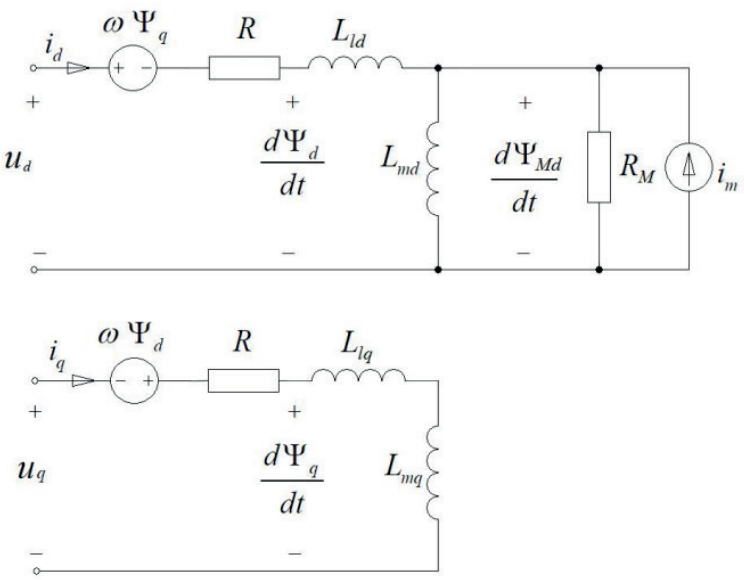

Figure 2 Equivalent circuit of the PMSM in d-axis and q-axis

Phasor diagram of the PMSM for motor operation is shown in Figure 3. The phasor diagram represents a stationary mode of operation, hence effective values for currents and voltages are used (indicated by capitals).

In Figure 3 the $E_{f}$ is the phase back electromotive force (EMF), or excitation voltage, induced in the stator winding by PMs at synchronous speed ( $E_{f}$ depends directly on rotor speed and PM flux), $I_{S}$ is the phase current, $R$ is the stator resistance, $X_{m d}$ and $X_{m q}$ are the d-axis and q-axis components of the synchronous reactance.

\section{Electromagnetic and construction design of synchronous motor with permanent magnets on external rotor}

Main results of the electromagnetic and construction design of synchronous motor with permanent magnets on external rotor is described in paper [8]. For the design and electromagnetic calculations of PMSM, the basic equations and information were used referring to [9-15]. The calculation of parameters and dimensions of SMPM was done by using a debugged $m$-file in MATLAB 2013a. Table 1 presents data of the designed motor. A schematic cross-section of the electromagnetic circuit with winding is presented in Figure 4.

\section{FEM Simulation of SMPM with external rotor}

The analytical design is validated by means of comparison to FEM simulations [8]. It was used in 2D FEM simulation that compared with $3 \mathrm{D}$ simulation needed a much shorter time to be calculated [16-19]. In the paper [8] presented are results from open-circuit and load simulation. The FEM simulation results correspond fairly well to the results obtained from the analytical design. The airgap flux density waveform of the machine at open-circuit simulation is presented in Figure 5. The backEMF waveforms of the machine at open-circuit simulation are presented in Figure 6. 
Table 1 Data of the PM synchronous motor [8]

\begin{tabular}{cccc}
\hline Quantity & Value & Quantity & Value \\
\hline rated power $[\mathrm{W}]$ & 250 & pole pieces of stator \\
rated voltage $[\mathrm{Vrms}]$ & 12 & pole pieces of rotor \\
rated speed $[\mathrm{rpm}]$ & 150 & number of coils per phase & 92 \\
outer machine diameter [mm] & 160 & number of turns per coil & number of winding layers \\
total machine width $[\mathrm{mm}]$ & 70 & & 36 \\
maximum torque $[\mathrm{Nm}]$ & 20 & & 2 \\
\hline
\end{tabular}

Table 2 Results from load simulation [8]

\begin{tabular}{cc}
\hline Quantity & Value \\
\hline Peak phase current [A] & 7.071 \\
Maximum rotor iron flux density [T] & 1.207 \\
Maximum stator iron flux density [T] & 1.949 \\
Fundamental airgap flux density [T] & 0.4558 \\
Peak flux linkage, q-axis [Wb] & 0.0452 \\
Peak flux linkage, d-axis [Wb] & 0.1122 \\
\hline
\end{tabular}

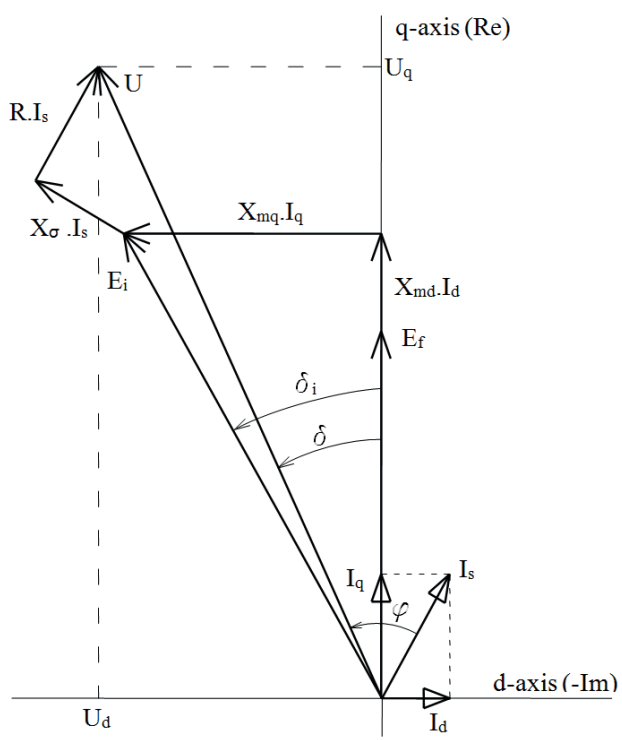

Figure 3 Phasor diagram of the PMSM in dq-axes

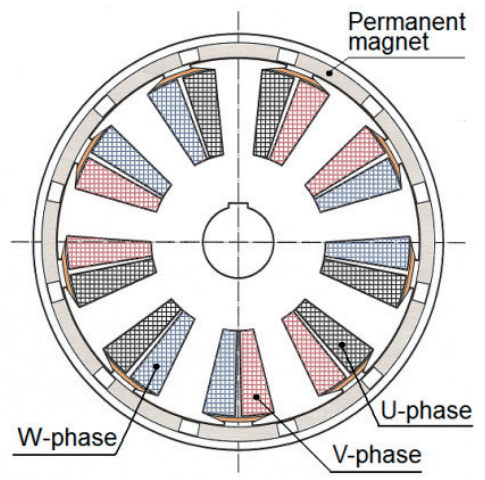

Figure 4 Electromagnetic circuit of SMPM [8]

Results from load simulation are presented in Table 2 and data for the torque motor at load simulation are presented in Table 3. The airgap flux density waveform of the machine at load
Table 3 Data of simulated torque of the motor [8]

\begin{tabular}{cc}
\hline Quantity & Value \\
\hline Mean airgap torque (by flux linkage and current) $[\mathrm{Nm}]$ & 9.047 \\
Mean airgap torque (by Maxwell stress tensor) [Nm] & 9.0 \\
Torque reduction due to iron losses [Nm] & 0.1868 \\
Torque ripple [\%] & 11.62 \\
\hline
\end{tabular}

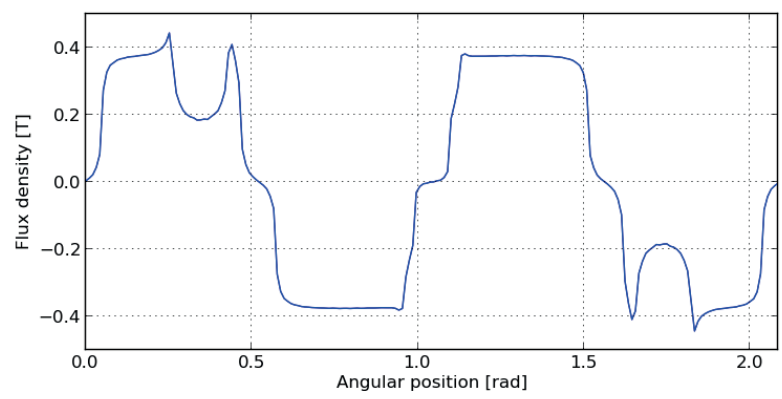

Figure 5 The airgap flux density waveform at open-circuit simulation [8]

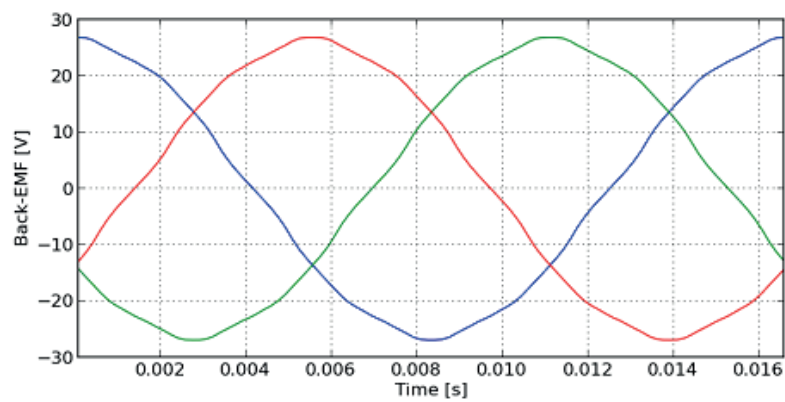

Figure 6 The back-EMF waveforms at open-circuit simulation [8]

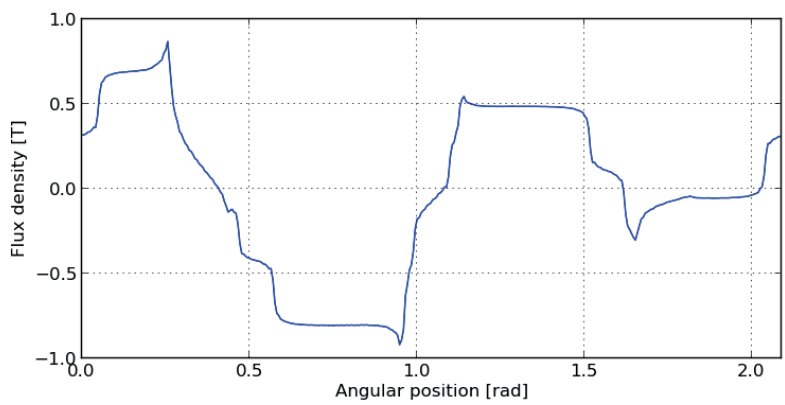

Figure 7 The airgap flux density waveform at load simulation [8]

simulation is presented in Figure 7. In Figure 8 presented is torque waveform of the machine at load simulation. 


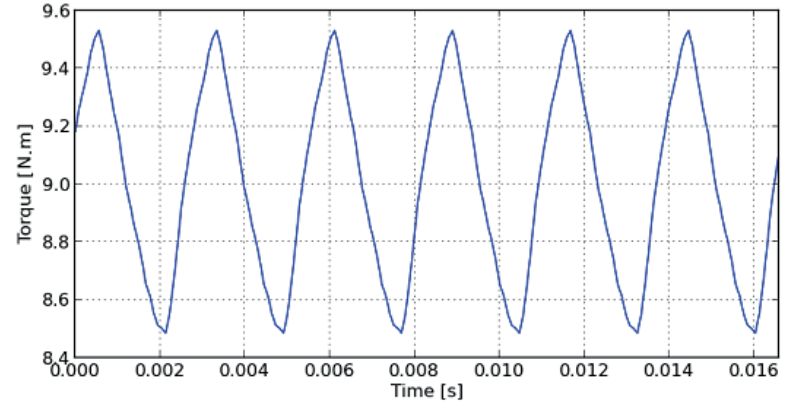

Figure 8 The torque waveform of SMPM at load simulation [8]

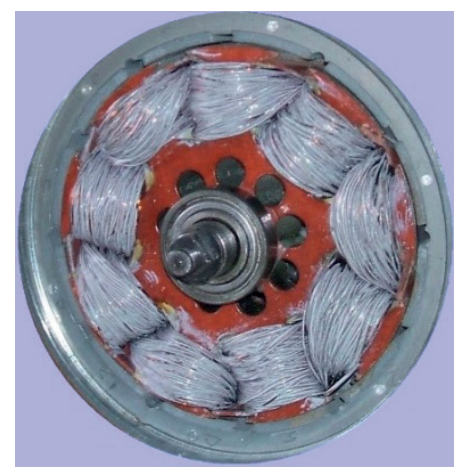

Figure 9 Photograph of prototype SMPM without bearing plate [8]

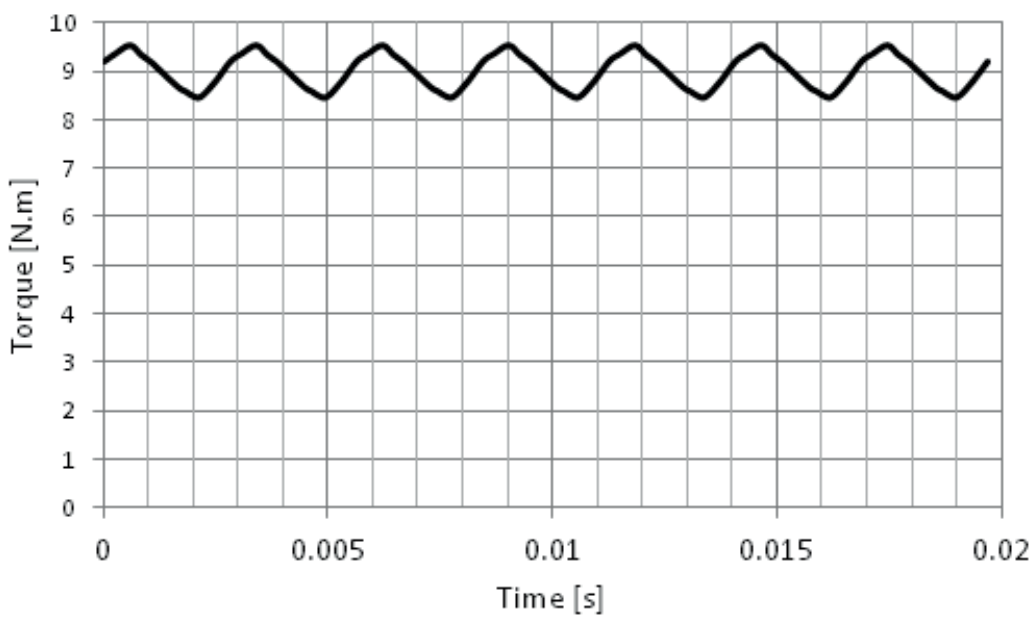

Figure 10 Torque as a function of time at the loading in motoric mode [8]

\section{Prototype of SMPM with external rotor and measured results of the machine}

The construction of prototype with outer rotor permanent magnet synchronous machine is described in [8] in detail. Photograph of the motor without bearing plate is shown in Figure 9.

Experimental measurements of the machine prototype were performed in laboratories. The motor was supplied from a frequency converter. Measurements of the stator quantity (voltage, current and frequency) were performed both on the frequency converter and measurement of the power on a digital wattmeter. The measurements were done in generator mode of operation for the speed of $200 \mathrm{rpm}$ and for two values of speed - 120 and $200 \mathrm{rpm}$ in the motor mode of operation, respectively. Measured torque ripple presented in Figure 10 is comparable with FEM simulation of torque (see Figure 8).

\section{Matlab/Simulink simulation of synchronous motor with permanent magnets on external rotor}

In this section presented are results of the mathematical model simulation created by Equations (4)-(10).

A) Simulation model of the permanent magnet synchronous motor

Matlab/Simulink ${ }^{\circledR}$ enables "to view" dynamic characteristics and to analyse transient performance of the motor. The mathematical model of the permanent magnet synchronous motor, is suitable for implementation of the Matlab/Simulink method based on $\mathrm{d}, \mathrm{q}$ transformations known from the reference frame theory of electrical machinery [20]. The mathematical model must correspond with the analysed motor and represents the physical phenomena as close as possible. The simulation model of the PMSM is presented in Figure 11.

The electromagnetic torque $T_{e m}$ in Fig. 11 is determined by Equation (6) and the loading torque $T_{L}$ can be expressed as follows:

$T_{L}=T_{e m}-J \cdot \frac{d \omega_{m}}{d t}$.

where $J$ is the rotor inertia and $\omega_{m}$ is angular speed of the rotor. The angular speed of the rotor is expressed by the time derivation of its displacement $\theta_{m}$ :

$\omega_{m}=\frac{d \theta_{m}}{d t}$.

The d-q components of the armature current $I_{S}$ of the PMSM (see Figure 3), in terms of the permanent magnet flux linkage $\Psi_{m d}$ and load angle $\delta$, are introduced.

\section{B) Simulation results}

On the basis of the simulation model of PMSM (see Figure 11), the simulation of torque, speed and current characteristics has been carried out. The stator windings parameters, flux linkage 


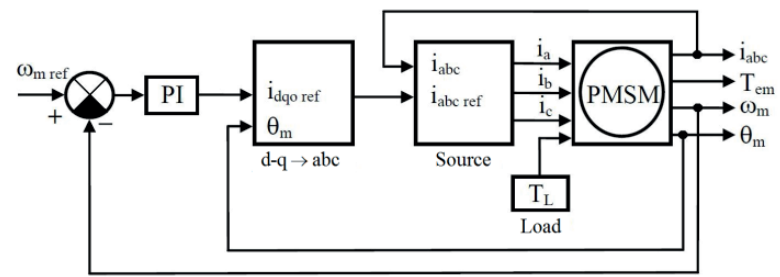

Figure 11 The simulation model of PMSM

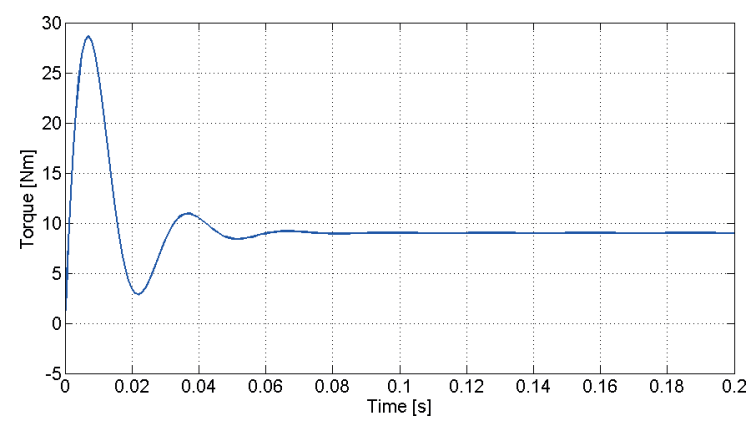

Figure 12 The dynamic torque characteristic of PMSM at rated load start-up

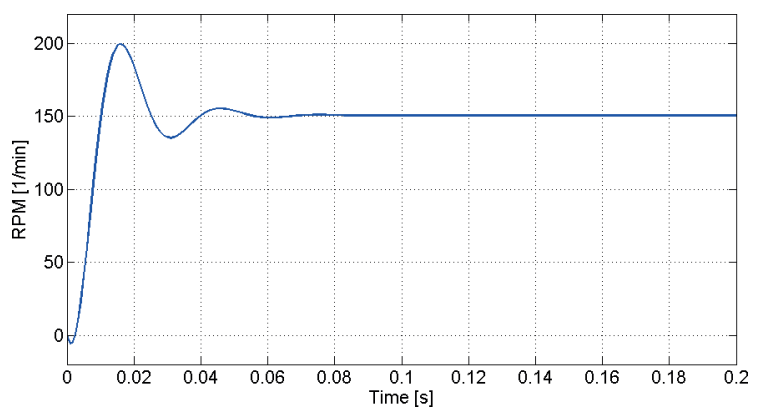

Figure 13 The mechanical speed of PMSM at rated load start-up

and synchronous $\mathrm{d}$ and $\mathrm{q}$ reactance of the motor are obtained from the FEM computations. The load torque is given as input data. The simulation procedure is performed for rated supply conditions and motor starting at the rated load $T_{L}=T_{N}$. The result of simulation torque characteristic for analyzed case is presented in Figure 12.

After the transients are suppressed, the obtained value of the simulated torque corresponds to the torque at the steady-state operating mode (see Table 3 ).

Figure 13 shows the mechanical speed of the PMSM. The stator currents are shown in Figures 14-16 respectively.

As it is shown in Figures 12-16, the PMSM has a good dynamic response.

\section{Conclusion}

The present paper describes the simulations and shows initial results of measurements of a synchronous machine prototype with an external rotor and permanent magnets. The design, FEM simulations and results of measurements are presented in paper [8].

The present paper shows the result of simulation of torque, mechanical speed and stator currents. The torque of the

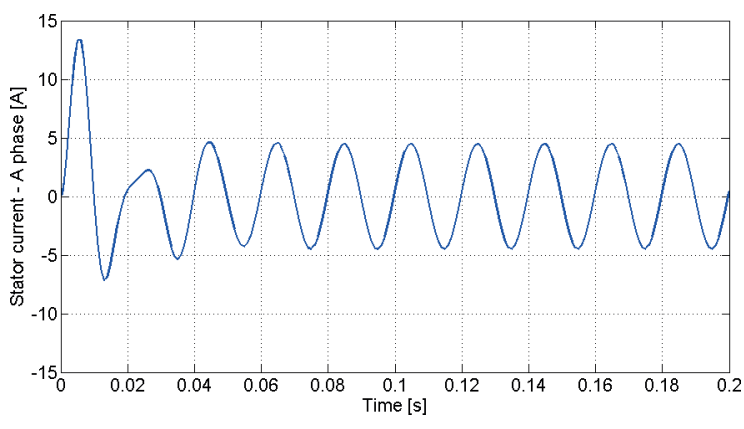

Figure 14 Motor stator current - A phase

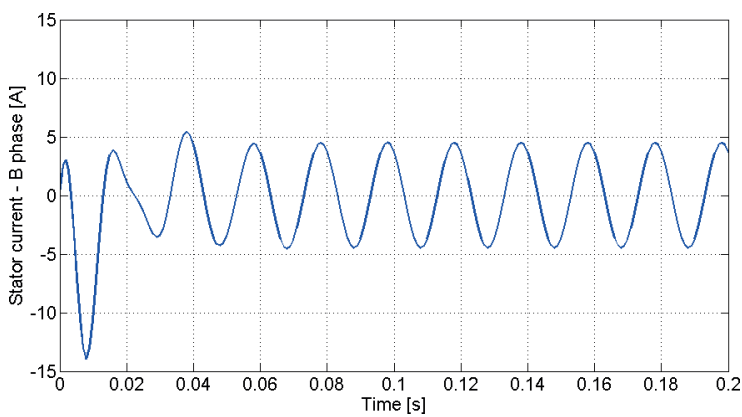

Figure 15 Motor stator current - $B$ phase

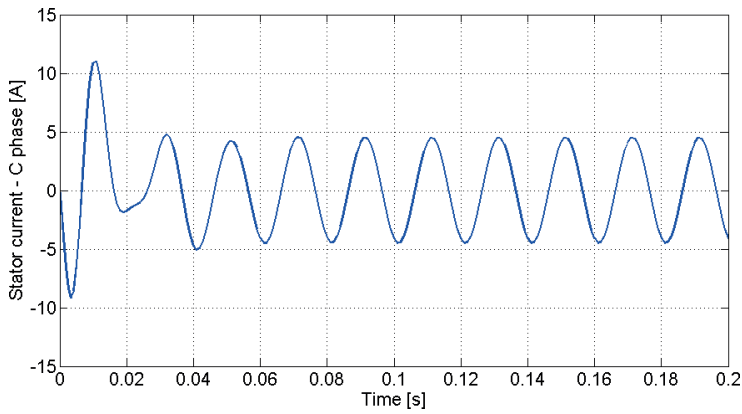

Figure 16 Motor stator current - $C$ phase

considered PMSM in present paper is verified in three ways: simulated results in Matlab/Simulink (Figure 12) and FEM Simulation (Figure 8 and Table 3) are compared with measured value (Figure 10). Showing a very good agreement, they prove that the applied methodologies as accurate.

Mechanical properties of the prototype of the inverse synchronous motor were verified too. The SMPM was supplied from the three-phase frequency converter at the speed corresponding to operation conditions. Results of measurements obtained at the constant speed in load mode, when the inverse synchronous motor was loaded up to $130 \%$ of the nominal current, confirm suitability of inverse synchronous motor for the direct drive in-wheel operation of the electric wheelchair. On the SMPM verified have been the dynamic properties. From the results one sees that the presented inverse SMPM has good dynamic and static properties.

\section{Acknowledgments}

The financial support of the Slovak Research and Development Agency under the contract no. APVV-16-0270 is acknowledged. 


\section{References}

[1] RUI-HUA, L., JIAN-FEI, Z., BO, H., GUO-QING, X. Adaptive inverse control of permanent magnet synchronous motor drive in a micro-electric vehicle. 8th International Conference on Machine Learning and Cybernetics : proceedings [online]. Vol. 4. Piscataway, NJ : IEEE, 2009. ISBN 978-1-4244-3703-0, p. 1909-1914. Available from: https://doi.org/10.1109/ICMLC.2009.5212190

[2] QIANFAN, Z., XIAOFEI, L. Permanent magnetic synchronous motor and drives applied on a mid-size hybrid electric car. Vehicle Power and Propulsion Conference VPPC ‘08 : proceedings. IEEE, 2008. ISBN 978-1-4244-1849-7, p. 1 - 5.

[3] SKALA, B. The heat and cooling of electronically switching synchronous machine as a main drive of a car. International Conference on Applied Electronics. IEEE, 2011, ISSN 1803-7232, p. 349-352.

[4] SATO, E. Permanent magnet synchronous motor drives for hybrid electric vehicles. IEEJ Transactions on electrical and electronic engineering [online]. 2007, 2(2), p. 162-168. eISSN 1931-4981. Available from: https://doi.org/10.1002/tee.20122

[5] SOONG, W. L., MILlER, T. J. E. Field-weakening performance of brushless synchronous AC motor drives. IEE Proceedings - Electric Power Application [online]. 1994, 141(6), p. 331-340. ISSN 1350-2352. Available from: https://doi.org/10.1049/ip-epa:19941470

[6] SCHIFERL, R. F., LIPO, T. A. Power capability of salient pole permanent magnet synchronous motor in variable speed drive applications. IEEE Transactions on Industry Applications [online]. 1990, 26(1), p. 115-123. ISSN 0093-9994, eISSN $1939-9367$. Available from: https://doi.org/10.1109/28.52682

[7] SEBASTIAN, T., SLEMON, G. R. Operating limits of inverter-driven permanent magnet motor drives. IEEE Transactions on Industry Applications [online]. 1987, 23(2), p. 327-333. ISSN 0093-9994, eISSN 1939-9367. Available from: https://doi.org/10.1109/TIA.1987.4504909

[8] KANUCH, J., GIROVSKY, P. Motor for direct drive of electric wheelchair. International Journal of Engineering Research in Africa [online]. 31, 2017, p. 94-103. ISSN 1663-4144. Available from: https://doi.org/10.4028/www.scientific.net/JERA.31.94

[9] OSIN, I. L., KOLESNIKOV, V. P., YUFEROV, F. M. Permanent magnet synchronous micromotors (in Rusian). Moscow, Energia 1976.

[10] GIERAS, J. F., WING, M. Permanent magnet motor technology, design and aplications. New York, Marcel Dekker, Inc., 2002. ISBN 0-8247-0739-7.

[11] CAMPBELL, P. Permanent magnet materials and their application. Cambridge, University Press, 1994. ISBN 0521249961.

[12] GIERAS, J. F. Analytical approach to cogging torque calculation in PM brushless motors. IEEE International Electric Machines and Drives Conference IEMDC'03 : proceedings. Vol. 2. 2003. eISBN 0-7803-7817-2, p. 815-819.

[13] SCHMIDT, E., SUSIC, M., EILENBERGER, A. Finite element analysis of an external rotor permanent magnet synchronous machine with star- and delta-connected tooth coil windings. XIX International Conference on Electrical Machines ICEM : proceedings [online]. IEEE, 2010. ISBN 978-1-4244-4175-4. Available from: https://doi.org/10.1109/ICELMACH.2010.5608233

[14] MARKO, R. Design of salient pole PM synchronous machines for a vehicle traction application - analysis and implementation. Ph.D. Thesis. University of Technology Lappeenranta, 2012. ISBN 978-952-265-337-6.

[15] BRANDT, M., GUTTEN, M., KOLTUNOWICZ, T., ZUKOWSKI, P. Analysis of winding fault in electric machines by frequency method. 12th International Conference ELEKTRO 2018 : proceedings [online]. 2018, p. 1-4. ISBN 978-1-5386-4758-5A. vailable from: https://doi.org/ 10.1109/ELEKTRO.2018.8398298

[16] SCHMIDT, E., EILENBERGER, A. Calculation of position dependent inductances of a permanent magnet synchronous machine with an external rotor by using voltage driven finite element analyses. IEEE Transactions on Magnetics [online]. 2009, 45(3), p. 1788-1791. ISSN 0018-9464, eISSN 1941-0069. Available from: https://doi.org/10.1109/TMAG.2009.2012822

[17] JIN, J. The finite element method in electromagnetics. 3. ed. New York: John Wiley \& Sons, 2014. ISBN 978-1-118-57136-1.

[18] BASTOS, J. P. A., SADOWSKI, N. Electromagnetic modeling by finite element methods. New York: Marcel Dekker Ltd., 2003. ISBN 0-8247-4269-9.

[19] PETKOVSKA, L., CVETKOVSKI, G. FEM based simulation of a permanent magnet synchronous motor performance characteristics. CES/IEEE 5th International Power Electronics and Motion Control Conference : proceedings [online]. Vol. 3. 2006. eISBN 1-4244-0448-7. Available from: https://doi.org/10.1109/IPEMC.2006.4777986

[20] ONG, CH-M. Dynamic simulation of electric machinery: using MATLAB/ SIMIULINK. New Jersey: Prentice Hall, 1998. ISBN 0137237855. 